\title{
The Relationship between Patients Referring Time at Hospitals and the Success of Operating Surgery Using Module Number (9): An Exploration Study in Ophthalmic Hospitals
}

\author{
Maysoon Abdulkareem Mohammad ${ }^{1} \&$ Khalaf Reshem Felah ${ }^{2}$ \\ ${ }^{1}$ Faculty of Business Administration, University of Mustansiriya Baghdad, Iraq \\ ${ }^{2}$ Department of Statistics, Faculty of Administration and Economics, Al-Mustansiriyah University, Iraq \\ Correspondence: Maysoon Abdulkareem Mohammad, Faculty of Business Administration, University of \\ Mustansiriya Baghdad, Iraq. E-mail:mys_abdula@yahoo.com
}

Received: May 26, 2019

Accepted: June 12, 2019

Online Published: July 9, 2019

doi:10.5539/ijbm.v14n8p126

URL: https://doi.org/10.5539/ijbm.v14n8p126

\begin{abstract}
The purpose of this research is to investigate the relationship between patients time attendance at hospitals and success of operative surgery using module number (9) from world health organization as scale to know the level of success.

Data were collected by questionnaire from a sample of (28) oculists which they worked in the ophthalmology department in Iraqi hospitals. The questionnaire involves (22) expressions used to obtain primary data that were analyzed using SPSS program. The result of research indicated that the majority of patients presented to hospitals at the appropriate time and minority of them attendance at the deadly time. Results also refer to strong and positive relationship between the success of surgical operation with referring at the appropriate time and existence of human and physical requirements together.
\end{abstract}

Keywords: time, success, operating surgery

\section{Introduction}

Through the various periods of human life time was considered as a major factor to perform goals either individual or organization. This fact is most important in the field of health because it related to human, especially in the recent years because of rising the level of health culture in all societies beside the progress in technical methods that used to treating diseases. This research attempts to find the patients' behavior that concern with their attendance at hospitals when they fell ill and to investigate the level of existence and availability of human and physical requirements that mentioned in module number (9) from world health organization in ophthalmic department and hospitals in Iraq.

\section{Background and Literature Review}

\subsection{Time Concept}

\subsubsection{Definition of Time}

Scientists and researchers had been given several definitions about time, but there is no single clearness of time that gather and determine all aspect concept. Time defined as something to deal with every day and something that everyone thinks they understand (Kelly et al., 2007), and also time refers to amount that its measure by o'clock and its part and it moves straight forward (Alsheny, 1993).

Time according to a current Dictionary is a continuous measurable quantity from the past through the present and into the future, and also a number of years, months, days representing such as interval. (Aoudi, 2006). Macmillan advanced learning dictionary state that time is a period either long or short during which you do something or something happens (Macmillan, 2007). Also defined as the thing that measured as seconds, minutes, hours, days.... etc. (Merriam, 2009).

Psychophysical research views time as a mental, construction which compares the perception of time to "clock" time (Macan, 1994). Sociological research that views as a social construction a convenience that culture agree on (Barreto.et al, 1991). 
Researchers in the field of management produce an additional explanation for the time such as (Hisrich et al, 2002), which Considered time as the most available assets to order to have an effective utilization of time. Table 1 display specification for them based on prior definitions.

Table 1. Specification of Time

\begin{tabular}{ll}
\hline Resource & Concept \\
\hline $\begin{array}{l}\text { Language Dictionaries } \\
\begin{array}{l}\text { Psychophysical } \\
\text { researchers }\end{array}\end{array}$ & $\begin{array}{l}\text { Quantity scale, such as (moment.... Year.... Decade..... Etc.) } \\
\text { A mental construction leads any person to perception and understand (his, her) activities. }\end{array}$ \\
$\begin{array}{ll}\text { Sociological researchers } \\
\text { Management researchers }\end{array}$ & $\begin{array}{l}\text { Social construction that is agreeable with individual, group and society culture. } \\
\text { An accessible thing owned by a person, group or company... etc. to perform their activities in order to obtain } \\
\text { benefits and advantages. }\end{array}$ \\
\hline
\end{tabular}

Source: Own researchers.

\subsubsection{Types of Time}

Researchers attempted to classify the time according to some unlikeness details Alhindawy was divided it into four types as follows (Alhindawy, 1999)

1. Creation time: It is related to the processes of thought, analysis, future planning, job organizing and performance appraisal.

2. Preparation time: It refers to a period time that is preceding work perform.

3. Production time: It indicates to a period of time that used in implementation tasks and activities that planned it in a creation time and readying in a preparation time.

4. Normal time: This class concern with time using in construct relationship with another organization and society.

In conformity with another researcher time can be divided into five kinds as following: (Alsheny, 1993)

1. Mechanical time: It refers to quantity scale, such as a moment, minute, hour, day, week.... Etc.

2. Biological time: It is related to growth and more complete to measure the evolution and developing phenomenon. It started with cells and ended with the animals.

3. Sociological time: It is relevant to important events and occasions such as birthday, war beginning and ending, obtaining a high qualification from a university..... Etc.

4. Psychological time: It is pointed out to selfish sense. Consequently, it is individual scale.

5. Metaphysical time: It is amply to the philosophy that examine the nature of existence. All people have not had more acknowledgment about it except the speech that state in the holy Koran and the bible.

Further, Doyle and his team on the effective use of time school had generated several time items as follows: (Doyle, 2013).

1. Available time that it refers to amount of accessible and obtained time for all school activities in a school year.

2. Allocated time that it indicates to distribute and designate the amount of time for instruction in the content area.

3. Engaged time that it mentions to the amount of time student is actively engaged in learning tasks.

4. Academic learning time that related to the amount of time successfully engaged in academic tasks.

Finally, to be identical with this research aim to clarify the relationship between time and surgical operating we can arrange it like this:

1. Appropriate time: It refers to enough time that allowed to give effectual treatment to patients before surgical operating. There is a high opportunity for success in this type.

2. Critical time: It indicates to tighten time that's required to offer over exertion from physicians' and their teams to remedying patients. In this type the chance of success is lower than the previous type. 
3. Deadly time: It means inanimate and fatal time that it occurs when the patients came to physicians after passing a lot time of illness and following grave complication. In this type there is maximum chance for success.

\subsubsection{Appropriate Time Concept}

Appropriate time refers to fitting time most people do or perform the thing through it. On the contrary negative results are appearance with high percentages. This is occurring if persons misunderstand the value of time for success in all aspects of their life.

Appropriate time can be named an effective time as called for scientists in the field of management when they agreed that time is a key to success or high degree of performance.

Appropriate time also indicates in conformity with our viewpoint to contrive time that it means using time exactly because it leads an individual to decide what must do.

Appropriate time related to our own activities to make sure that they are accomplished with the available or allocated time (Marshan et al., 2004). It is indispensable to mention that person's behavior is important to conduct time right because time assessment, behavior is aimed at awareness of here and now, past, present and future and self-awareness of one's time use. (Fox et al., 2000).

Performing tasks in appropriate time require to remove errors of human behavior by planning the way and person acts (Macan, 1996).

Accordingly, using the time correctly permit a person to assign a specific time to achieve duties and activities as per their importance and have a preference.

\subsubsection{Successful Operating Surgery Concept}

A successful is a sign of achieving a certain level of responsibility in one's career (Bloching, 2015), and also defined as the achievement of something attempted (Aoudi, 2006). Successful in another ward indicated to high performance that means a general emphasis on engaged empowered work force and on high quality goods and services (Batt, 2009).

Marschan mentioned that high performance is when an organization is so excellent in so many areas that it consistently out performance most of the competitions for extended periods of time (Marschan, 2004). Health in the recent time becomes more sophisticated and more importance beside the medical level has greatly improved. World health organization state number of indications we can use as a scale for measuring successful operative surgery. This indication can be divided into three parts as:

Part one: Structural indication that involves following point: (Birkmeyer et al., 2004)

1. Procedure volume that it used as a proxy for surgical quality.

2. Staff level of training.

3. Organize persons in a hospital.

4. Availability of up to date technology.

5. Financial resource.

Part two: Process indication that refers to the types of treatment that patients receive and routinely used in nonsurgical field and also used as object to represent the surgical process, including operating room and operating room cleaning in operating room surgery (Birkmeyer et al., 2004), (Koller, 2009), (Harper, 002).

Part three: Outcome indication: The outcomes are considered the gold standard as assesses the value of the services provided (Birkmeyer.et al, 2004:630), (Yorston. D, 2002:543). It includes:

1. Improve quality of patient life.

2. Mortality rate.

3. Length of stay.

4. Complication rate.

5. Readmission rate.

6. Patient satisfaction.

Moreover, there are other factors had been affected on success of operating surgery and surgical quality like As:

1. Surgical safety. 
2. Operating room.

3. Schedule of operating.

Patient safety is one of the greatest challenges in the health and it remains a daily challenge in the operating room (Cook, 2005), (Houdenhove, 2012). The World health organization has developed (19) items to check surgical safety as shown in table 2 .

An operating room is one of the most demanding department in hospitals (Harper et al., 2002), and it has significant influence on patient care (Cook, 2005). In the hospitals there are logical steps explain the flow process in the operating room that starts with surgery schedule and ending with delivery back towards (Cook, 2005).

The scheduling of operating in the health service sector plays an important role in achieving their goals. This goal to meet the patient satisfaction by minimizing waiting time because longer waiting can worsen the patient's disease (Fie, 2012; Haynes, 2011).

Table 2. Surgical safety checklist

\begin{tabular}{|c|c|c|}
\hline Before induction of anesthesia & Before Skin incision & Before the patient leaves the operating room \\
\hline $\begin{array}{l}\text { With at least nurse and anesthetist } \\
\text { Mass the patient confirmed his- her } \\
\text { identity site, procedures and consent? } \\
\text { Yes }\end{array}$ & $\begin{array}{l}\text { With nurse anesthetist surgeon } \\
\text { Confirm all team members have introduced } \\
\text { by name and role }\end{array}$ & $\begin{array}{l}\text { With nurse, anesthetist and surgeon } \\
\text { Nurse verbally confirms: } \\
\text { 冈 The name of procedures } \\
\text { 冈 Completion of instrument, sponge and } \\
\text { needle counts. } \\
\text { 冈 Whether equipment problems to be } \\
\text { addressed }\end{array}$ \\
\hline $\begin{array}{l}\text { Is the site marked? } \\
\text { Yes } \\
\text { Not applicable. }\end{array}$ & $\begin{array}{l}\text { Confirm the patient's name procedure and } \\
\text { where he in the ci-soon will be made. }\end{array}$ & $\begin{array}{l}\text { To surgeon, Anesthetist and nurse: } \\
\text { W What are the key concerns for recovery } \\
\text { an management of the patient? }\end{array}$ \\
\hline $\begin{array}{l}\text { Is the anesthesia machine and medication, } \\
\text { check completing? } \\
\text { Yes }\end{array}$ & $\begin{array}{l}\text { The Mas antibiotic porphy lake's been given } \\
\text { within the last } 6 \mathrm{p} \text { minut } \\
\text { Yes. } \\
\text { No }\end{array}$ & \\
\hline $\begin{array}{l}\text { Is the pulse oximeter on the patient and } \\
\text { functioning? } \\
\text { Yes }\end{array}$ & 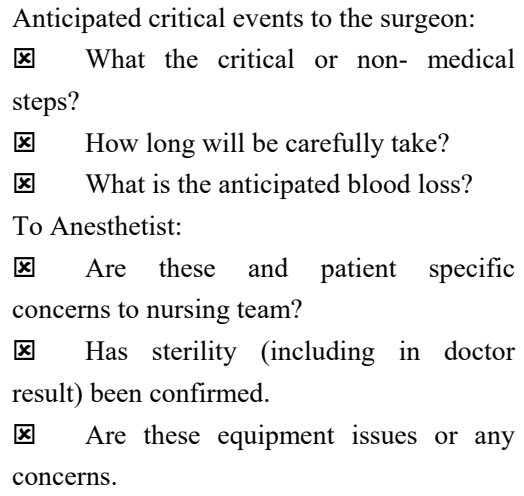 & \\
\hline $\begin{array}{l}\text { Dose the patient have a: known allergy? } \\
\text { Yes } \\
\text { No }\end{array}$ & $\begin{array}{l}\text { Is essential imaging displayed? } \\
\text { Yes } \\
\text { No applicable }\end{array}$ & \\
\hline $\begin{array}{l}\text { Difficult airway or aspiration risk? } \\
\text { Yes } \\
\text { No }\end{array}$ & & \\
\hline $\begin{array}{l}\text { Risk of } 500 \mathrm{ml} \text { blood loss }(7 \mathrm{ml} / \mathrm{kg} \text { in } \\
\text { children }) ? \\
\text { Yes } \\
\text { No }\end{array}$ & & \\
\hline
\end{tabular}

Source: World Health Organization, 2009. 


\section{Research Methodology}

This part explains the research design that involves problem determining, research objectives, hypothesizes, population sample, procedures of data collection, techniques of data analysis and testing the hypothesizes and variables that impact on patients referring to medical centers beside the relationship between patents attendance time with success of operating surgery.

\subsection{Research Problems}

Time is a great interest variable to anybody, groups and organizations to achieve and a accomplish desired goals and objectives. This fact is most necessities for patients when they need to get a prosperous treatment because any delayed at referring medical centers bring to a negative result. On the other hand a success of surgical operating had been depending on availability of suitable structure and processes used in medical centers. Therefore, research problems can be determined through the following questions:

1) What is the percentage of patient's attendance at medical centers just they aware that their health is not well?

2) What are the levels of requirements and facilities prepared in medical centers?

3) What is the relationship between a successful operating surgery and patient's attendance to the medical center at the appropriate time?

\subsection{Research Objectives}

This research aims to

1) Overview time, meaning, types of time, effective time, successful operating surgery, and condition of surgical operating according to world health organization.

2) Investigate what type of time which patients used it widely when they were referring at medical centers.

3) Define the importance of patients' attendance at appropriate time to obtain positive healthy results.

4) Explain the significance preparing requirements and facilities of operative surgery completely.

5) Illustrate the relationship between patient attendance at appropriate time to the medical center and the success of operative surgery.

\subsection{Research Population and Sample}

For the purpose of meaningful and convent accomplishment of this research number of hospitals in different cities in Iraq have been selected as afield to study. The population consists of specialist oculists and the sample was chosen through friends, relatives and other acquaintances-stances which we used to locate as potential respondents. We distributed a questionnaire directly to (31) oculists in a capital and several cities of Iraq. The number of initial replies received was (31). After screening first round replies three application forms were completed. Therefore (28) respondents were taken from this research table 4 illustrate accurate numbers of questions in a questionnaire that subordinate to analysis.

This research mainly based primary data originating from a survey. For this purpose, we constructed a questionnaire involved (22) expressions to investigate replies opinions. The scale has five choices suit with physician 's opinion as a display in table 3 .

Table 3. Likert points

\begin{tabular}{llllll}
\hline Opinions & Strongly agree & Agree & Partly agree & Disagree & Strongly disagree \\
\hline Points & 05 & 04 & 03 & 02 & 01 \\
\hline
\end{tabular}

The SPSS statics software package was used for statistical analysis. The following medium was used in this research:

1) Percentage.

2) Weighted mean.

3) Standard deviation.

4) Standard error. 
5) Pearson Correlation.

6) T- Test.

Table 4. Allotment questionnaire

\begin{tabular}{ll}
\hline Variables & Q.N \\
\hline Affective factors for patient attendance & 1 \\
Types of patient attendance & 2.3 .4 .5 .6 \\
Existence of surgical requirements & 7.8 .9 .10 .11 .12 .13 .14 \\
Outcomes are measured & 15.16 .17 .18 .19 .20 .21 .22 \\
\hline
\end{tabular}

\subsection{Research Hypotheses}

The under listed hypotheses (Null) were used to guide the conduct of the research

1) $\mathrm{Ho}_{1}$ : The patients' time referring at hospitals is not significant relation with success of operating surgery.

2) $\mathrm{Ho}_{2}$ : The existence and availability of human and physical requirements in hospitals do not significantly influence for success of operating surgery.

\subsection{Research Limitation}

The main problem faced the researchers was it hardly to find enough free time owned by physicians' admit them to discuss and full questionnaire form because they spent most of their time in public hospitals, private health centre and individual clinic further family affair.

\section{Data Analysis}

\subsection{Validity and Reliability}

Face validity was used to validate the research tool. So, the questionnaire as a present was distributed between five professors and specialists. Then we were amended based on their notices.

After that a sample size of (8) oculists was chosen and the questionnaire subjected using test and re-test with a gap of two weeks between the two test administration. Reliability of the variables used in the research was tested using cronbach's Alpha. The result indicated good reliability of test items above (0.8). Table 5 identified the results of cronbach's Alpha.

Table 5. Cronbach's Alpha

\begin{tabular}{lll}
\hline Variables & Survey questions & Cronbach's Alpha coefficient \\
\hline Ways of patients, referring and get accurately diagnosed & 2.3 .4 .5 .6 & 0.883 \\
Affecting factors of patients, referring hospitals & 1 & 0.922 \\
Surgical operating requirements & 7.8 .9 .10 .11 .12 .13 .14 & 0.882 \\
Outcomes measurement & 15.16 .17 .18 .19 .20 .21 .22 & 0.801 \\
\hline
\end{tabular}

Source: Statistical analysis.

\subsection{Analysis the Ways of Patients, Referring at Hospitals and Getting Suitable Treatment}

Table 6 classified the responses of the research sample about survey questions related to ways of patients, referring at ophthalmic hospitals and health centers and methods of diagnosed malady and received treatment according to Likert five point scale 
Table 6. Ways of patients, referring hospitals

\begin{tabular}{llllll}
\hline $\begin{array}{l}\text { Q.N } \\
\text { Options }\end{array}$ & Strongly agree & Agree & Partly agree & Disagree & Strongly disagree \\
\hline 2 & 06 & 08 & 10 & 03 & 01 \\
3 & 09 & 11 & 08 & - & - \\
4 & 06 & 07 & 08 & 01 & 06 \\
5 & 06 & 11 & 06 & 03 & 02 \\
6 & 14 & 06 & 08 & - & - \\
Average & 8.2 & 8.6 & 8.0 & 1.4 & 1.8 \\
Percentage & 29.285 & 30.714 & 28.517 & 5.0 & 6.428 \\
\hline
\end{tabular}

Table 7 based on data that display in the prior table show the value of types patients' attendance and taking suitable treatment. The finding of table 6 and table 7 indicated to the positive state for patients, attendance at appropriate, timely and taking suitable treatment, whereas the percentage reached at (60) while the percentage of patients, referring at critical time arrived to (28.5) and percentage of patients present at the deadly time was (11-5).

Table 8 come out the means, standard division and standard error for survey questions concern with types of time that used by patients when they attendance to hospitals and also the kind of treatment that patients received. The finding refers to the value above than the intermediate rate of patients, referring at the appropriate time and taking suitable treatment, whereas the average mean was (3.67) at the same time we can notice that the value of standard division and standard error were decreased. This result indicative of right ideal of the research sample further it was supporting. The results that appear in the previous tables.

Table 7. The Percentage of Ways of Patients attendance

\begin{tabular}{llll}
\hline Time types & Scale & Nearly number & Percentage \\
\hline Appropriate & Strongly agree +agree & 17 & $60-72$ \\
Critical & Partly agree & 08 & $28-57$ \\
Deadly & Disagree + strongly disagree & 03 & $10-711$ \\
Total & $=$ & 28 & 100 \\
\hline
\end{tabular}

Source: Statistical analysis.

Table 8. Means, STD.division, STD.errors for types of patients' attendance

\begin{tabular}{llll}
\hline Q.N & Mean & $\begin{array}{l}\text { Std } \\
\text { Division }\end{array}$ & $\begin{array}{l}\text { Std } \\
\text { Error }\end{array}$ \\
\hline 2 & & 0.59044 & 0.04742 \\
3 & 3.53 & 0.42153 & 0.06124 \\
4 & 4.10 & 0.86005 & 0.07149 \\
5 & 2.93 & 0.61421 & 0.08424 \\
6 & 3.57 & 0.48207 & 0.09772 \\
Average & 3.21 & 0.59380 & 0.07242 \\
\hline
\end{tabular}

Source: Statistical analysis.

\subsection{Analysis and Determinate Impact Factors for Patients' Attendance}

Table 9 shows the rank of decisive factors that had been affected on patient, referring at the appropriate time since health, culture was represented as a firstly factor while the financial cost comes as a latest factor, and also we can determine patients' health culture and bad services thought owns by patients are the important factors that have strengthened the influence for patients, attendance. These factors were building closed (70) percentage, and it indicates to high level of impression. 
Table 9. Ranking of influence factors on patients, attendance

\begin{tabular}{llll}
\hline Factor & Replies number & Rank & Percentage \\
\hline Health culture & 11 & 01 & 39.286 \\
Financial cost & 01 & 05 & 03.572 \\
Fearing from operating result & 06 & 03 & 21.428 \\
Bad services conviction & 08 & 02 & 28.571 \\
Treatment hopeless & 02 & 04 & 07.143 \\
Total & 28 & ---- & 100 \\
\hline
\end{tabular}

Source: Statistical analysis.

\subsection{Analysis the Existence of Requirement}

In the table 10 we illustrated the viewpoint of oculists which choose as a sample of research about the existence and availability of human and physical requirements and facilities that it demands to perform a successful operating surgery using a quintuple scale. The finding refers to positive, powerful concern with the existence and availability of requirements and facilities in the ophthalmic hospitals and health centers. The positive percentage reached at (78) while the opposite percentage about (6) as a display in tables $(10,11)$ the opposite result is very low and it does not influence

Table 10. Oculists viewpoint about existence of requirements

\begin{tabular}{|c|c|c|c|c|c|c|}
\hline Q.N & Strongly agree & Agree & Partly agree & Disagree & $\begin{array}{l}\text { Strongly } \\
\text { disagree }\end{array}$ & Tota \\
\hline 7 & 16 & 09 & 03 & ------- & ------- & 28 \\
\hline 8 & 13 & 08 & 07 & ------- & ------ & 28 \\
\hline 9 & 17 & 09 & 02 & ------ & ------ & 28 \\
\hline 10 & 11 & 08 & 06 & 03 & ------ & 28 \\
\hline 11 & 09 & 10 & 07 & 02 & ------- & 28 \\
\hline 12 & 07 & 06 & 06 & 09 & ------- & 28 \\
\hline 13 & 15 & 09 & 04 & ------- & ------- & 28 \\
\hline 14 & 16 & 11 & 01 & ------ & ------ & 28 \\
\hline Average & 13 & 8.75 & 4.5 & 1.75 & 00 & 28 \\
\hline Percentage & 46.428 & 31.25 & 16.071 & 6.25 & 00 & 100 \\
\hline
\end{tabular}

Source: Statistical analysis.

Table 11. Percentage of existence requirement

\begin{tabular}{|c|c|c|c|}
\hline Result & Details & Percentage & Total \\
\hline \multirow[t]{2}{*}{ Positive } & -Strongly agree & 46.428 & 77.678 \\
\hline & -Agree & 31.250 & \\
\hline Neutrally & - Partly agree & 16.071 & 16.071 \\
\hline \multirow[t]{2}{*}{ Negative } & -Disagree strongly & 6.25 & 6.25 \\
\hline & - Disagree & 0,00 & \\
\hline
\end{tabular}

Source: Statistical analysis.

Finally, it is important to mention that the questions related to a smooth movement of the surgical operating stage, clearness procedure, using recent technical by physicians and checking patients completely obtained full mark almost. Table 12 demonstrated several statically analyses belong existence and availability requirements in hospitals and health centers. The finding point out to rising value of the means for all expressions using to measure this variable and at the same time decreased the standard deviations and standard errors. Therefore, this result makes sure and support the results that emerged in tables $(10,11)$. Moreover, we can deduct and say according to prior results that the ophthalmic hospitals and health centers are ready and able to achieve surgical operating with a high level of success. 
Table 12. Means, STD.division, STD.errors for existence of requirements

\begin{tabular}{llll}
\hline Q.N & Mean & $\begin{array}{l}\text { Std } \\
\text { Division }\end{array}$ & $\begin{array}{l}\text { Std } \\
\text { Error }\end{array}$ \\
\hline 7 & & 0.312 & 0.02714 \\
8 & 4.464 & 0.526 & 0.04622 \\
9 & 4.214 & 0.412 & 0.03523 \\
10 & 4.535 & 0.526 & 0.03441 \\
11 & 3.964 & 0.715 & 0.04125 \\
12 & 3.928 & 0.913 & 0.04613 \\
13 & 3.392 & 0.472 & 0.03127 \\
14 & 4.392 & 0.392 & 0.02862 \\
Average & 4.535 & 0.507 & 0.03628 \\
\hline
\end{tabular}

\subsection{Measuring Success of Operating Surgery}

With respect to measure the level of operative surgery based on principles and demands that mentioned in (Module 9) from world health organization for measuring surgical outcomes were strongly positive according to the viewpoint of oculists. This viewpoint confirmed the success of operating surgery that perform in hospitals. The positive percentage that refers to success is above (91) while the negative percentage is exactly (zero) as illustrated in table $(10,11)$

Finally, these results indicate to identify and harmonize with an index of the World Health Organization.

Table 13. Measuring outcomes

\begin{tabular}{lllllll}
\hline $\begin{array}{lllll}\text { Q.N } \\
\text { Options }\end{array}$ & Strongly agree & Agree & Partly agree & Disagree & Strongly disagree & Total \\
\hline 15 & 22 & 06 & ------- & ------ & ------ & 28 \\
16 & 21 & 07 & ------ & ------ & ------ & 28 \\
17 & 20 & 08 & ------ & ----- & ------ & 28 \\
18 & 16 & 06 & 06 & ------ & ------ & 28 \\
19 & 20 & 07 & 01 & ------ & ------ & 28 \\
20 & 21 & 07 & ------ & ------ & ------ & 28 \\
21 & 13 & 09 & 07 & ------ & ------ & 28 \\
22 & 14 & 07 & 07 & ------ & ------ & 28 \\
23 & 21 & 07 & ------ & ----- & ----- & \\
Average & 18.67 & 7.0 & 2.23 & ------ & ------ & 28 \\
Percentage & 66.678 & 25.00 & 8.321 & ------ & ------ & 100 \\
\hline
\end{tabular}

Source: Statistical analysis.

Table 14. Percentage of outcomes

\begin{tabular}{llll}
\hline Result & Details & Percentage & Total \\
\hline Positive & -Strongly agree & 66.678 & 91.678 \\
& - Agree & 25.00 & \\
Neutrally & -Partly agree & 8.321 & 08.221 \\
Negative & -Disagree strongly - disagree & ------ & ----- \\
\end{tabular}

Source: Statistical analysis.

Table 15 show means, standard divisions and standard errors for the expressions that used to measure the outcomes of surgical operations. The value of means going up extremely whereas the value of average means about (4.6) while the values of standard deviations and standard errors were going down. This means consistency and agreement with finding that appeared in prior tables and also indicated two corresponded and harmonize the responses of research samples. 
Table 15. Means, STD.division, STD.errors for operating outcomes

\begin{tabular}{llll}
\hline Q.N & Mean & $\begin{array}{l}\text { Std } \\
\text { Division }\end{array}$ & $\begin{array}{l}\text { Std } \\
\text { Error }\end{array}$ \\
\hline 15 & & 0.371 & 0.03616 \\
16 & 4.786 & 0.329 & 0.03162 \\
17 & 4.750 & 0.357 & 0.03102 \\
18 & 4.714 & 0.416 & 0.06237 \\
19 & 4.357 & 0.382 & 0.03511 \\
20 & 4.678 & 0.323 & 0.05216 \\
21 & 4.750 & 0.391 & 0.03162 \\
22 & 4.214 & 0.362 & 0.03162 \\
Average & 4.250 & 0.362 & 0.03755 \\
\hline
\end{tabular}

\subsection{Test of Research Hypothesizes}

Test of Null Hypothesis (1)

In order to test this null hypothesis two variables were identified as following

a) Patients time referring at hospitals.

b) Success of operative surgery.

The value of correlation between the two previous variables was (0.84).

This means that a strong and positive relationship exists between patient time attendance hospitals and the success of surgical operations. To ascertain the statistical significance of this relation, the t-test computed and the calculated t-value ( $\mathrm{t} c$ ) of (3.051) was observed. At (2) degree of freedom and (95\%) confidence level the value of t-table (tt) was obtained (2.13). Meanwhile, since t-test calculated value ( $\mathrm{t} c$ ) of (3.051) is greater than t-test table value (t) of (2.13). Therefore, the relation is statically significant. According to this, the null hypothesis which states the patients, time referring at hospitals are not significantly relation with success of operating surgery is rejected while the alternative hypothesis is accepted. This means that the patients time attendance at hospitals is affected on success of operating surgery. The result of correlation and t-test is shown in table (16).

Test of Null Hypothesis (2)

The second null hypothesis state that the existence and availability of human and physical requirements in hospitals do not significantly influence for success of operating surgery. The correlation analysis results that display in table 16 for the relation between existence of requirements and surgical operation successfully shows an R-value of (0.852) and t-test result of (2.802). The R-value of (0.852) means that the existence and available of human and physical requirements in hospitals could significantly affect on success of operating surgery. From the statistics on the relationship it is clear that the (t) calculated value (t c) of (2.802) is greater than the t-test table value (tt) of (2.13) obtained at (0.95) level of confidence and two degrees of freedom. Therefore, the relationship is statistically significant. On the basis of thus the null hypothesis number (2) is rejected while the alternative hypothesis is accepted. This means that the existence and availability of human and physical requirements in hospitals are affected on success of surgical operations.

Table 16. Finding of hypothesis

\begin{tabular}{|c|c|c|c|c|c|c|c|}
\hline HYP number & Variables & & $\mathrm{R}$ & Def & Conf & $\mathrm{T} \mathrm{c}$ & $\mathrm{Tt}$ \\
\hline 1 & $\begin{array}{l}\bullet \\
\text { hospitals }\end{array}$ & Patients time attendance at & 0.84 & 2 & 0.95 & 3.501 & 2.13 \\
\hline & $\bullet$ & Success of operative surgery & & & & & \\
\hline 2 & $\bullet$ & $\begin{array}{l}\text { Existence of requirements } \\
\text { Success of operative surgery }\end{array}$ & 0.85 & 2 & 0.95 & 2.802 & 2.13 \\
\hline
\end{tabular}

\section{Summary Conclusion}

On the basis of applied study, we can conclude by coming after points:

1) Most of the patients were attendance and taking suitable treatment at the appropriate time, whereas the percentage of (60). 
2) There are inconsiderable patients referring to hospitals at a critical time, whereas the percentage of (28.5) roughly.

3) There are just (11.5) percentage of patients presented at the deadly time.

4) The health culture was the first factor affected on patients' attendance to hospitals at the appropriate time while the financial cost was the latest.

5) There are high percentage refers to existing and available of requirements that demands to get and perform successful operative surgery whereas the percentage raised in (78).

6) There are positive and strong relationships between the success of surgical operation on the side with existence and available of human and physical requirements and patients, attendance at appropriate time to gather on the other side.

7) The outcomes of operative surgery in ophthalmic hospitals were identical and harmonize with indications and conditions of the world health organization that state in module number (9).

\section{Discussion of Findings and Recommendation}

From analysis of data and hypothesizes, we discovered that there were high level of success surgical operations in the field of ophthalmology and also there were high grade of agreement with World Health Organization conditions and require. The results refer to exist these conditions and requirement of the high percentage in ophthalmic department and health centers in Iraq. This success, according to our viewpoint related with the physicians having high skill and they worked hard to get outstanding performance, and the success also concern with increasing understanding and awareness of people for importance attendance to specialist health center or expert physician at appropriate time to receive and taking suitable treatment.

Based on previous finding, the researchers have introduced some recommendations as follows:

1) Seriously working with the ministry of health to support ophthalmic hospitals and oculists through encouraging them to give creative performance and providing requirements that it is necessary to get successful surgery to hospitals with high quality.

2) Increasing training programs for physicians and their assessments' to rise and maintained by outstanding performance.

3) Increasing the participation of media to spread widely knowing belong health culture.

4) Working to generalization and universalization the experience of oculists and ophthalmic hospitals to other field of medicine.

5) Making other studies to find success rate and to determine other factors that it influence for success of operating surgery.

\section{References}

Aoudi, A. (2006). A current Dictionary for Learning. Lebanon: Modern Institute for Books.

Barreto, L. (1991). Studies on Time: Biological, Psychological and Social Time. Institute of Advanced Studies of the University of SaoPaulo .

Batt, R. (2003). Human Resource Practices. Industrial Relations, 24(3).

Batt, R. (2009). Managing Customer Services: Human Resource Practices. Academy of Management, 45(3).

Bloshing, S. (2015). What does the world most successful, British Council Center.

Cook, R. (2005). A model of system dynamics and consequences for patient safety. Quality, Safe Health Care, 14(130). https://quaritysasety.bmi.com.

Doyle, P. (2013). Classroom organization and management in the handbook and research in teaching (3rd ed.). New York, Macmillan.

Fie, H. (n.d.). A planning and Scheduling problem for an open scheduling strategy. Journal of Computer and Industrial Engineering, 58.

Fox, S. (2000). Inerrability Communication: Theoretical perspective. Handbook of Communication.

Harper, P. (2002). Modeling for the planning and management of bed capacities in hospitals. Journal of Operational Research Sociology, 53(11).

Hayness, A. (2011). Surgical outcomes measurement for a global population. Surgery, 149(4). 
Hisrich. R. (2002), Effective time management for high performance in organizations. Journal of Nigerian Institute of Management, 44(3).

Hondenhoven, P. (2012). Improving Operating room efficiency. Anesthesia and Analgesia, 105(3). https://Journals/ww.com/anesthesia-analgesia/pages/currenttoc.aspx.

Kelly, E. (2007). Rethinking the clockwork of work. Development, Human Resource, 9.

Koller, A. (2009). Process modeling of ICU patient flow. Journal of Medical System, 33(25).

Macan, T. (1996). Time management training. Journal of Psychology, 130(3).

Macan, T. (1996). Time management. Journal of Applied Psychology, 79.

Marschan, R. (2004). Handbook of qualitative research methods for international business. England: Edward Elgar Publishing.

Potenza, B. (2009). Lessons learned from the institution of the surgical care improvement project at a teaching medical center. American Journal of Surgery, 198(6).

Yorston, D. (2002). Does prospective monitoring improve cataract surgery outcomes in Africa. British Journal of Ophthalmology, 82 .

\section{Copyrights}

Copyright for this article is retained by the author(s), with first publication rights granted to the journal.

This is an open-access article distributed under the terms and conditions of the Creative Commons Attribution license (http://creativecommons.org/licenses/by/4.0/). 